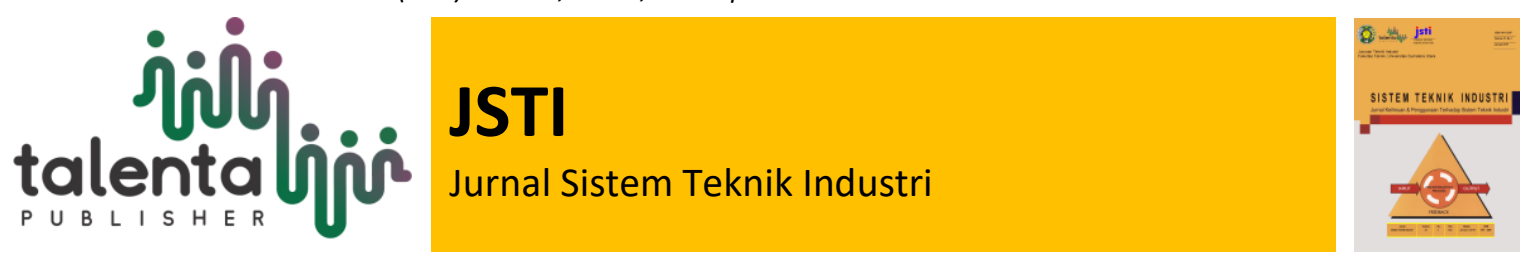

\title{
Analisis Kesehatan Dan Keselamatan Kerja Menggunakan Failure Mode And Effect Analysis Di PT. XYZ
}

\author{
Muhammad Ramadan ${ }^{1}$, Sukanta ${ }^{2}$, Risma Fitriani ${ }^{3}$ \\ ${ }^{1,2,3}$ Fakultas Teknik, Universitas Singaperbangsa Karawang, Karawang
}

\begin{abstract}
Occupational Health and Safety (OHS) is important to maintain and improve so that the quality of human resources in the company is always in prime condition. Every company has a different level or level of Occupational Health and Safety (OHS). PT. XYZ is a company that uses corrosive materials, therefore Occupational Health and Safety (OHS) analyst at PT XYZ is needed. The Occupational Health and Safety (OHS) analysis carried out in this study used the FMEA method to determine which part of the production process had Occupational Health and Safety (OHS) that needed repair the most. From the research results, it was found that the highest Risk Priority Number (RPN) value was the pickling and degreasing production process.
\end{abstract}

Keyword: OHS, Failure and Mode Effect Analysis, FMEA

\begin{abstract}
Abstrak. Keselamatan dan Kesehatan Kerja (K3) penting untuk dijaga dan ditingkatkan agar kualitas sumber daya manusia di perusahaan selalu prima. Setiap perusahaan memiliki tingkatan Keselamatan dan Kesehatan Kerja (K3) yang berbeda. PT. XYZ merupakan perusahaan yang menggunakan material korosif, oleh karena itu dibutuhkan analis Keselamatan dan Kesehatan Kerja (K3) di PT XYZ. Analisis Keselamatan dan Kesehatan Kerja (K3) yang dilakukan pada penelitian ini menggunakan metode FMEA untuk menentukan bagian mana dari proses produksi yang memiliki Keselamatan dan Kesehatan Kerja (K3) yang paling membutuhkan perbaikan. Dari hasil penelitian diketahui bahwa nilai Risk Priority Number (RPN) tertinggi pada proses produksi pickling dan degreasing.
\end{abstract}

Kata Kunci: K3, Failure and Mode Effect Analysis, FMEA

Received 23 November 2020 | Revised 16 January 2021 | Accepted 23 January 2021

\section{Latar Belakang}

Industri di Indonesia merupakan salah satu faktor pendapatan negara dan juga merupakan salah satu tempat yang menyediakan lapangan pekerjaan bagi sebagian rakyat Indonesia. Negara mendapatkan pendapatan pajak dari industri, baik dari pajak penghasilan maupun pajak pertambahan nilai. Suatu industri diperlukan sumber daya manusia, oleh karena itu bisa

${ }^{*}$ Corresponding author at: Universitas Singaperbangsa Karawang

E-mail address: muhammad.ramadan16094@student.uniska.ac.id https://doi.org/10.32734/jsti.v23i1.4959 Attribution-NonCommercial 4.0 International. Some rights reserved Copyright @ 2021 Published by Talenta Publisher, ISSN: 1411-5247 e-ISSN: 2527-9408

Journal Homepage: http://talenta.usu.ac.id/jsti 
beroperasi dengan maksimal juga menjadi salah satu tempat yang menyediakan lapangan pekerjaan.

Badan Pusat Statistik Nasional Indonesia salah satu kajiannya bahwa industri yang terdata pada tahun 2019 berjumlah 33.923 perusahaan. Perusahaan tersebut diklasifikasikan menjadi dua yaitu perusahaan industri sedang dengan jumlah karyawan sebanyak 20 sampai 99 orang dan perusahaan industri besar yang memiliki jumlah karyawan lebih dari 99 orang [1]. Hal ini menunjukkan bahwa perusahaan industri di Indonesia sedikit banyaknya berpengaruh pada rakyat maupun negara. Pada perusahaan industri banyak faktor yang menyebabkan perusahaan industri tersebut sukses dan gagal. Salah satu faktornya adalah faktor keselamatan dan kesehatan kerja (K3) dalam lingkungan perusahaan industri tersebut. Menurut mantan Menteri Ketenagakerjaan tahun 2019, bahwa kecelakaan kerja akan menyebabkan kematian, namun juga terjadi kerugian materi, moril dan pencemaran lingkungan, juga berpengaruh pada produktivitas dan kesejahteraan masyarakat.

Direktur Pelayanan BPJS Ketenagakerjaan juga menjelaskan bahwa rata-rata pelayanan yang dilakukan oleh BPJS ketenagakerjaan akibat kecelakaan kerja dengan rata-rata sebesar 130.000 kasus setiap tahunnya. Kasus kecelakaan kerja tersebut meliputi dari kasus ringan sampai kasus yang berdampak fatal. Namun dari 130.000 kasus tersebut, kasus kecelakaan kerja ringan masih mendominasi dan biasanya kasus ringan tersebut terjadi pada lingkungan kerja pada perusahaan industri [2]. Oleh sebab itu penting untuk suatu perusahaan industri dalam penerapan K3 yang mereka miliki agar mengurangi kecelakaan kerja. Pemerintah pusat berusaha agar bisa memberi motivasi kepada perusahaan, pemerintah daerah maupun pekerja untuk menerapkan K3 dengan cara memberikan penghargaan terkait K3 pada tahun 2019, dan diberikan penghargaan terhadap 1.052 perusahaan yang tidak memiliki kasus kecelakaan kerja atau zero accident [3].

Perusahaan yang telah menerapkan SMK3 dengan baik juga akan diberikan penghargaan keberhasilan penerapan SMK3 dan perusahaan yang menerima penghargaan tersebut sebanyak 1.466 perusahaan. Juga bagi perusahaan yang melakukan program pencegahan penyakit HIV AIDS juga diberikan penghargaan dan diketahui ada 172 perusahaan yang menerima penghargaan tersebut. Dan untuk penghargaan terakhir adalah penghargaan yang diterima oleh 17 gubernur yaitu penghargaan pembina $\mathrm{K} 3$ terbaik [3]. Jika dibandingkan jumlah pemenang penghargaan dengan jumlah perusahaan industri yang ada di Indonesia pada tahun 2019 maka dapat disimpulkan bahwa masih banyak perusahaan masih belum menerapkan $\mathrm{K} 3$ dengan baik.

Penelitian di perusahaan industri ini yang bergerak dalam bidang surface finishing part otomotif, yang menggunakan bahan-bahan korosif yang berbahaya jika tidak di gunakan dengan baik dalam pengendalian K3 nya. Metode penelitian yang digunakan adalah metode Failure Mode and Effects Analysis (FMEA). Metode FMEA merupakan metode yang sistematis dan digunakan untuk mengidentifikasikan sistem dan juga mencegah masalah sistem, produk dan proses sebelum masalah terjadi. Adapun alas an menggunakan metode FMEA karena tidak memiliki data 
kecelakaan kerja pada perusahaan industri dengan lengkap. Dengan menggunakan metode FMEA ini dapat memudahkan untuk menganalisis dan memberikan penilaian terhadap K3 walaupun tidak memiliki data kecelakaan kerja sebelumnya. Selain itu, juga metode FMEA juga dapat memberikan penilaian dengan menghitung risk priority numbers (RPN).

\section{Tinjauan Pustaka}

\subsection{Keselamatan dan Kesehatan Kerja}

Keselamatan dan Kesehatan Kerja (K3) merupakan kegiatan untuk menjamin agar terciptanya kondisi lingkungan kerja yang aman dan nyaman, juga terhindar dari gangguan-gangguan baik fisik maupun mental. Dengan demikian maka diperlukan pembinaan melalui seperti pelatihan, pengarahan, dan pemantauan terhadap pelaksanaan tugas para pekerja dan sosialisasi regulasi dan informasi yang jelas, baik dari lembaga pemerintah maupun perusahaan tempat dimana pekerja tersebut melakukan pekerjaannya [4].

K3 adalah sebuah hak asasi manusia, dimana harus selalu sadar bahwa penerapan K3 itu sangat penting untuk para pekerja dan pengusaha agar dapat membangkitkan, mengingatkan dan membiasakan dalam penerapan K3 yang baik dan benar [5]. Hal ini diupayakan melalui penerapan K3 di suatu perusahaan industri. Kesehatan kerja para pekerja dalam ilmu kesehatan akan dicari tindakan untuk memperbaiki dan mencegah kecelakaan kerja yang berulang pada lingkungan tersebut, juga diharapkan agar para pekerja dan masyarakat di sekitar lingkungan perusahaan terhindar dari bahaya. Untuk mengetahui hal-hal yang menyebabkan kecelakaan kerja dapat dilakukan dengan memberikan penilaian terhadap faktor apa saja yang menyebabkan kecelakaan kerja atau penyakit yang dialami akibat lingkungan kerja dan perusahaan, hal tersebut diukur dan kemudian hasilnya digunakan untuk tujuan korektif [6]. Semua kegiatan yang dilakukan harus selalu ada dalam ruang lingkup K3 dikarenakan segala ancaman kecelakaan kerja bisa saja terjadi dimanapun dan kapanpun. Ruang lingkup K3 tersebut diharapkan selalu ada baik pada sektor formal atau nonformal [7].

Penerapan K3 juga memiliki banyak manfaat bagi perusahaan menurut Tarwaka dalam diantaranya adalah sebelum terjadinya kecelakaan dan menyebabkan banyak kerugian, pihak manajemen diharapkan sudah mengetahui kelemahan sistem operasional [8]. Selanjutnya patuh terhadap perundangan mengenai $\mathrm{K} 3$, dan dapat meningkatkan produktivitas para pekerja di perusahaan tersebut.

Menurut Undang-undang No.1 Tahun 1970 berkaitan dengan Keselamatan Kerja, bahwa tujuan K3 adalah bagaimana yang berhubungan dengan sumberdaya seperti mesin, peralatan, area tempat kerja dan lingkungan tempat kerja agar dapat mencegah terjadinya kecelakaan dan sakit akibat kerja, memberikan perlindungan pada sumber-sumber produksi sehingga dapat meningkatkan aman, nyaman, efisiensi dan produktivitas [9]. 


\subsection{Failure Mode and Effect Analysis (FMEA)}

Metode FMEA merupakan sebuah metode analisa dan evaluasi untuk mengetahui kemungkinan terjadinya sebuah kegagalan pada sistem, desain, proses untuk dibuat langkah penanganannya. Dalam FMEA setiap kemungkinan kegagalan yang terjadi dikuantifikasi untuk dibuat prioritas penanganan [10]. Metode FMEA fokus pada untuk mengetahui penyebab kerusakan dan proses terjadinya suatu kerusakan, dilakukan dengan cara mengidentifikasi penyebab dan proses kerusakan untuk setiap failure mode. Langkah selanjutnya adalah memberikan saran waktu pelaksanaan kegiatan preventive maintenance yang bertujuan untuk menurunkan angka tingkat kegagalan, sehingga segala bentuk kegagalan potensial dapat dikurangi atau ditekan menggunakan langkah pencegahan yang didasarkan pada prioritas. Cara menentukan skala prioritas adalah dengan cara mendapatkan nilai risk priority number (RPN). Nilai RPN tersebut menunjukkan tingkat prioritas untuk melakukan perbaikan terhadap komponen ataupun area yang ada di dalam sistem tersebut [11].

Salah satu alat yang sering digunakan dalam praktik bisnis performance improvement adalah metode FMEA. Metode FMEA ini juga merupakan metode pertama yang tercipta untuk menganalisa suatu kesalahan atau kegagalan pada proses. Metode FMEA pertama kali dirumuskan sekitar tahun 1950 an. Metode FMEA melibatkan sangat banyak komponen, sub sitem serta perangkat guna identifikasi kegagalan, termasuk penyebab yang timbul pada setiap proses [12].

Metode FMEA dapat menganaslisis pola kegagalan dan akibat identifikasi adanya potensi bahaya, penilaian dan pengendalian risiko yang melibatkan analisis modus kegagalan dari suatu entitas, penyebab, dampaknya, dan hubungan kritikalitas dari kegagalan [13]. Menurut [14] bahwa dalam konteks K3, kegagalan merupakan definisi di atas merupakan suatu bahaya yang muncul dari suatu proses. Faktor-faktor penilaian dalam metode FMEA sebagai berikut:

1. Severity (S), adalah penentuan tingkat kuantifikasi seberapa serius kondisiyang diakibatkan jika terjadi kegagalan. Severity dinilai pada skala 1-5.

2. Occurance $(\mathrm{O})$, adalah penentuan tingkat kemungkinan terjadinya kegagalan. Occurance $(\mathrm{O})$ dinilai pada skala 1-5. Dimana, hampir tidak pernah terjadi (1) sampai yang paling mungkin terjadi atau sulit dihindari (5).

3. Detection (D), adalah penentuan untuk menunjukkan tingkat kemungkinan penyebab kegagalan dapat lolos dari pengendalian yang sudah dipasang. Level untuk detection juga dari 1-5, dimana pada skala angka 1 menunjukkan kemungkinan pasti terdeteksi, dan 5 menunjukkan kemungkinan tidak terdeteksi adalah sangat besar.

4. Risk Priority Number (RPN), adalah penentuan terhadap hasil perkalian dari nilai ranking severity, occurance, dan detection. 


\section{Metodologi Penelitian}

Metode penelitian merupakan suatu cara untuk melakukan awal penelitian, proses dan analisa serta menyimpulkan . Pada tahap pengumpulan data yang diperlukan. Tabel 1 menunjukkan teknik pengumpulan data sebagai berikut :

Tabel 1 Teknik Pengumpulan Data

\begin{tabular}{llll}
\hline No & \multicolumn{1}{c}{ Jenis Data } & \multicolumn{1}{c}{ Metode } & \multicolumn{1}{c}{ Sumber Data } \\
\hline $\mathbf{1}$ & Data Umum & Wawancara & Pemimpin \\
\hline $\mathbf{2}$ & Seluruh alur kegiatan & Observasi & Kondisi lapangan \\
\hline $\mathbf{3}$ & Kecelakaan Kerja & Observasi dan wawancara & Kondisi lapangan dan para pegawai \\
\hline
\end{tabular}

\subsection{Prosedur Identifikasi Bahaya}

Prosedur identifikasi bahaya digunakan untuk mengetahui hal-hal yang harus dilakukan untuk menjalankan proses penilaian K3, sebagai berikut:

1. Menetapkan dan memelihara prosedur untuk identifikasi bahaya, menilai resiko dan menerapkan tindakan pengendalian yang diperlukan, yang meliputi:

- Aktifitas rutin dilakukan dan tidak rutin dilakukan dilingkungan Perusahaan.

- Berlaku atas semua orang yang mempunyai akses ketempat kerja (termasuk subkontrak dan tamu) di Perusahaan.

- Fasilitas yang terdapat pada lingkungan kerja, baik itu disediakan oleh pihak diluar perusahaan ataupun disediakan oleh perusahaan itu sendiri.

2. Penetapan suatu identifikasi bahaya, kemudian penilaian resiko dan penerapan tindakan pengendalian yang diperlukan sesuai ruang lingkup, sifat dan waktu dilakukan oleh perusahaan. sebelum terjadinya kecelakaan yang lebih besar (proaktif). Identifikasi dilakukan mengikuti perubahan aktifitas atau kegiatan yang terjadi.

3. Melakukan identifikasi dan evaluasi aspek K3 dengan perhitungan harus dilakukan secara teratur dan terus menerus untuk memastikan tidak adannya penyimpangan dalam pelaksanaan operasi K3.

- Melaksanakan identifikasi aspek K3 dilapangan dalam ruang lingkup perusahaan.

- Apabila termasuk dalam kriteria aspek K3, maka dilaksanakan pengisian form "Evaluasi dari indentifikasi bahaya, penilaian dan pengendalian Resiko".

- Kondisi berpengaruh dengan K3, yaitu :

- Normal

Keadaan aktifitas atau proses yang berlangsung dengan tidak ada perubahan selama aktifitas (proses) yang terjadi sesuai dengan prosedur yang berlaku.

- Abnormal

Keadaan aktifitas atau proses yang berlangsung tidak sesuai dengan prosedur atau instruksi kerja sehingga terjadi hal-hal diluar kondisi normal. Keadaan abnormal bisa terjadi akibat kesalahan prosedur pengoperasian, adanya perbaikan atau hal-hal lain. 
- Kondisi darurat yang berpotensi

Keadaan aktifitas atau proses yang sama sekali tidak dikehendaki (contoh kebakaran, listrik padam, banjir) yang diperkirakan bisa terjadi.

- Kriteria yang membuat dampak berbahaya dikelompokkan berdasarkan topik, yaitu :

- Mekanik, mesin (pesawat tenaga, mesin transmisi, pesawat angkat, mesin kerja produksi).

- Listrik

- Api, kebakaran, peledakan

- Terbentur benda, kejatuhan benda

- Tertimbun

- Kerja tangan, perkakas tangan

- bahan-bahan kimia, Bahan korosif

- Transport (Ranmor, KA, Kapal)

- Keracunan, dan lain-lain.

\subsection{Kriteria Evaluasi Penilaian dan Pengendalian Resiko}

Evaluasi penilaian dan pengendalian resiko memiliki kriteria-kriteria yang akan dijadikan acuan untuk analisis FMEA. Kriteria-kriteria tersebut dibagi menjadi tiga yaitu kriteria penilaian akibat dari kerugian dan dilambangkan huruf $(a)$, kriteria yang kedua adalah penilaian peluang yang dapat terjadi dan dilambangkan dengan huruf $(b)$ sedangkan yang terakhir adalah analisis tingkat resiko (seringnya terjadi kecelakaan) dan dilambangkan dengan huruf $(c)$, ketiga kriteria ini masing-masing memiliki nilai terhadap setiap kecelakaan kerja yang terjadi pada perusahaan.

\subsection{Kriteria Penilaian Akibat dari Kerugian atau Kerusakan (a)}

Kriteria-kriteria penilaian akibat dari kerugian perusahaan diantaranya berupa kerugian-kerugian yang berdampak besar bagi kesehatan dan juga berdampak pada kerugian-kerugian materi baik kecil, sedang ataupun besar. Kesehatan yang diidentifikasikan sebagai salah satu kerugian adalah cacat, kematian, cidera ringan, kehilangan hari kerja dan lain-lain. Sedangkan kerugian materi juga diperhitungkan sebagai akibat kerusakan yang telah terjadi pada saat bekerja didalam perusahaan. Kriteria ini diterangkan pada Tabel 2 yaitu kriteria penilaian akibat dari kerugian atau kerusakan.

Tabel 2 Penilaian Akibat dari Kerugian atau Kerusakan (a)

\begin{tabular}{ll}
\hline \multicolumn{1}{c}{ Klasifikasi } & $\boldsymbol{a}$ \\
\hline Tidak cidera, kerugian material kecil & 1 \\
Cidera ringan/P3K, kerugian material sedang & 2 \\
Hilang hari kerja, kerugian material cukup besar & 3 \\
Cacat pekerja, kerugian material besar & 4 \\
Kematian, keugian material sangat besar & 5 \\
\hline
\end{tabular}




\subsection{Kriteria Penilaian Peluang yang Dapat Terjadi $(b)$}

Penilaian peluang yang dapat terjadi dilambangkan dengan huruf $b$. Kriteria dalam penilaian ini diklasifikasikan 5 (lima) yaitu pasti akan terjadi (almost certain), cenderungakan terjadi (likely), kemungkin bisa terjadi, kemungkinan kecil akan terjadi (unlikely), dan sangat jarang terjadi (rare). Kelima klasifikasi tersebut memiliki nilai peluang masing-masing. Nilai tersebut digunakan untuk mengidentifikasi peluang kecelakaan kerja yang akan terjadi selanjutnya, hal ini menjadi penting agar perusahaan bisa mengetahui penyebab dan solusi dari permasalahan tersebut. Selanjutnya akan diterangkan pada Tabel 3.

Tabel 3 Penilaian Peluang yang Dapat Terjadi $(b)$

\begin{tabular}{lcc}
\hline \multicolumn{1}{c}{ Klasifikasi } & Simbol & $\boldsymbol{b}$ \\
\hline Hampir pasti bisa terjadi & $\mathrm{A}$ & 5 \\
Cenderung akan terjadi & $\mathrm{B}$ & 4 \\
Kemungkinan bisa terjadi & $\mathrm{C}$ & 3 \\
Kemungkinan kecil bisaterjadi & $\mathrm{D}$ & 2 \\
Sangat jarang terjadi & $\mathrm{E}$ & 1 \\
\hline
\end{tabular}

\subsection{Analisis Tingkat Resiko (Seringnya Terjadi Kecelakaan) (c)}

Analisis tingkat resiko dilambangkan dengan huruf c, klasifikasi analisis ini dibagi menjadi 4 bagian diantaranya adalah Resiko ekstrim (Extreme Risk), Resiko tinggi (High Risk), Resiko sedang (Moderat Risk), Resiko rendah (Low Risk). Empat bagian tersebut memiliki nilai masingmasing yang berguna sebagai analisis tingkat resiko diukur dengan seringnya terjadi kecelakaan terbut pada bagian produksi perusahaan tersebut. Klasifikasi tersebut selengkapnya akan diterangkan pada Tabel 4.

Tabel 4 Analisis Tingkat Resiko

\begin{tabular}{lcc}
\hline \multicolumn{1}{c}{ Klasifikasi } & Simbol & c \\
\hline Resiko Ekstrim (Extreme risk) & $\mathrm{E}$ & 5 \\
Resiko Tinggi (High risk) & $\mathrm{H}$ & 4 \\
Resiko Sedang (Moderat risk) & $\mathrm{M}$ & 3 \\
Resiko Rendah (Low risk) & $\mathrm{L}$ & 2 \\
Resiko Ekstrim (Extreme risk) & $\mathrm{E}$ & 1 \\
\hline
\end{tabular}

Penilaian risiko didapatkan dari Akibat (Keseriusan, kerugian, kerusakan, Peluang (kemungkinan) dan frekuensi kejadian dalam setiap periodanya.

$$
\text { Nilai Risiko }=a \times b \times c
$$

Dimana :

a : Akibat Kerugian dan Kerusakan

$b \quad$ : Peluang yang dapat terjadi

c : Analisis Tingkat Resiko 


\section{Hasil dan Pembahasan}

\subsection{Data Proses Kegiatan}

Alur proses produksi perusahaan dimulai dari pengambilan parst dari supplier, setelah itu partpart tersebut akan ditempatkan dibagian warehouse (gudang). Selanjutnya part-part tersebut di bawa ke bagian produksi untuk diproses produksi. Setelah produk selesai, selanjutnya dilakukan pengecekan kualitas produk tersebut untuk memeriksa kesesuaian spesifikasinya di bagian quality control (QC). Setelah pengecekan di QC apakah produk sudah sesuai dengan standar, jika suda hsesuai maka produk dikirim ke gudang barang jadi. Alur proses kegiatan tersebut dapat dilihat pada Gambar 1 yang akan dijelaskan dibawah ini:

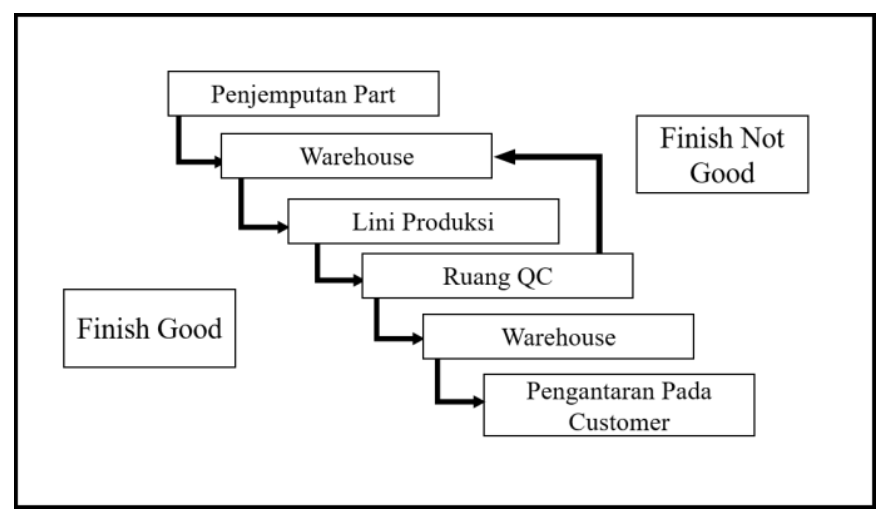

Gambar 1 Alur Kegiatan proses produksi

\subsection{Pengolahan Data}

Pengolahan data yang dilakukan pada penelitian ini untuk mencari penyebab terjadinya kecelakaan kerja pada bagian produksi, dari hasil pengumpulan data baik data primer maupun data sekunder ke bagian produksi. Setelah diketahui data-data jenis kecelakaan apa yang sering terjadi pada bagian produksi maka langkah selanjutnya mengidentifikasikan penyebab kecelakaan kerja pada bagian produksi tersebut. Setelah dilakukan penentuan tingkat keparahan (severity), kemungkinan akan terjadi (Occurance) dan deteksi (detection). Analisis hasil dari pengolahan data yang sudah dilakukan sebelumnya dapat dimulai dengan menilai resiko dengan cara melakukan perkalian dari nilai akibat (keseriusan, kerusakan, dan kerugian), nilai peluang akan terjadi kecelakaan, dan nilai frekuensi yang terjadi dalam setiap periodenya. Tabel 5 di bawah ini menunjukkan hasil penilaian risiko untuk menentukan nilai risk priority numbers (RPN).

Tabel 5 Perhitungan Nilai Resiko

\begin{tabular}{clrccc}
\hline \multirow{2}{*}{ Lambang } & \multicolumn{1}{c}{ Kegiatan } & \multicolumn{3}{c}{ Penilaian Resiko } & Nilai Resiko \\
\cline { 3 - 4 } & & $\mathrm{a}$ & $\mathrm{b}$ & $\mathrm{c}$ & (RPN) \\
\hline A & Pengangkutan part 1 & 2 & 4 & 3 & 24 \\
B & Pengantaran part menggunakan kendaraan & 5 & 1 & 3 & 15 \\
C & Penurunan part & 2 & 4 & 3 & 24 \\
D & Pengambilan part dari gudang & 1 & 4 & 2 & 8 \\
E & Pelaksanaan proses degreasing & 4 & 4 & 4 & 64 \\
F & Proses water rising 1 & 2 & 4 & 3 & 24 \\
\hline
\end{tabular}




\begin{tabular}{clcccc}
\hline G & Pelaksanaan proses pickling & 4 & 4 & 4 & 64 \\
H & Proses water rinsing 2 & 2 & 4 & 3 & 24 \\
I & Pelaksanaan proses elektroplating & 4 & 4 & 4 & 64 \\
J & Proses water rinsing 3 & 1 & 3 & 1 & 3 \\
K & Proses activating & 1 & 4 & 2 & 16 \\
L & Proses water rinsing 4 & 1 & 3 & 1 & 3 \\
M & Proses Chroming & 1 & 4 & 2 & 8 \\
N & Proses water rinsing 5 & 1 & 1 & 1 & 1 \\
O & Proses drying & 1 & 1 & 1 & 1 \\
P & Pemindahan part & 2 & 4 & 3 & 24 \\
Q & Proses inspeksi & 1 & 5 & 3 & 15 \\
R & Pengangkutan part 2 & 2 & 4 & 3 & 24 \\
S & Pengantaran part kepada customer & 5 & 1 & 3 & 15 \\
\hline
\end{tabular}

Nilai-nilai tabel 5 di atas diurutkan terlebih dahulu nilai RPN dari yang terkecil hingga terbesar, maka hasilnya pada tabel 6 di bawah ini:

Tabel 6 Pengurutan Nilai RPN

\begin{tabular}{ccc}
\hline Nomor & Kegiatan & Nilai resiko (RPN) \\
\hline 1 & N & 1 \\
2 & O & 1 \\
3 & J & 3 \\
4 & L & 3 \\
5 & D & 8 \\
6 & M & 8 \\
7 & B & 15 \\
8 & Q & 15 \\
9 & S & 15 \\
10 & K & 16 \\
11 & A & 24 \\
12 & C & 24 \\
13 & F & 24 \\
14 & H & 24 \\
15 & P & 24 \\
16 & R & 24 \\
17 & Q & 15 \\
18 & S & 15 \\
\hline
\end{tabular}

Setelah diketahui nilai-nilai tersebut, selanjutnya menghitung nilai rata-rata Risk Priority Number (RPN) nilai tengah, kuartil atas dan kuartil bawah. Hasil perhitungan dengan persamaan (2) dan (3) berikut.

$$
\begin{gathered}
\text { Rata-rata nilai RPN }=\frac{\text { Jumlah seluruh nilai RPN }}{\text { Banyak nilai RPN }} \\
\text { Nilai Tengah }=\frac{\text { Banyak nilai RPN }}{2}+0,5
\end{gathered}
$$

1. Rata-rata nilai $\mathrm{RPN}=\frac{421}{19}=22,158$

2. Nilai Tengah $=\frac{19}{2}+0,5=10$ (nilai ke 10$)$

Selanjutnya kuartil atas dan bawah akan ditentukan sebagai berikut: 
1. Quartil atas adalah nilai di atas nilai tengah (10), maka didapatkan hasil yaitu data 11 sampai dengan data 19.

2. Quartil bawah adalah nilai di bawah nilai tengah (10), maka didapatkan hasil yaitu data 1 sampai dengan data 9 .

Tabel 7 di bawah ini menunjukkan bahwa dapat dilakukan analisis per kegiatan setiap lokasi kegiatan dapat juga dinilai RPN sebagai berikut:

Tabel 7 Penilaian RPN dengan Menganalisis Per-Lokasi Kegiatan

\begin{tabular}{ccc}
\hline Lokasi & Kegiatan & RPN \\
\hline \multirow{2}{*}{ Customer } & $\mathrm{A}$ & 24 \\
& $\mathrm{~B}$ & 15 \\
\hline \multirow{3}{*}{ Warehouse } & $\mathrm{C}$ & 24 \\
\hline \multirow{5}{*}{ Produksi } & $\mathrm{D}$ & 8 \\
& $\mathrm{E}$ & 64 \\
& $\mathrm{~F}$ & 24 \\
$\mathrm{~F}$ & $\mathrm{G}$ & 64 \\
\hline \multirow{5}{*}{ Produksi } & $\mathrm{H}$ & 24 \\
& $\mathrm{I}$ & 64 \\
& $\mathrm{~J}$ & 3 \\
& $\mathrm{~K}$ & 16 \\
& $\mathrm{~L}$ & 3 \\
\multirow{2}{*}{ Quality Control } & $\mathrm{M}$ & 8 \\
& $\mathrm{~N}$ & 1 \\
\multirow{2}{*}{ Warehouse } & $\mathrm{O}$ & 1 \\
& $\mathrm{P}$ & 24 \\
& $\mathrm{Q}$ & 15 \\
\hline
\end{tabular}

Berdasarkan tabel 7 tersebut diketahui bahwa ada 5 lokasi yaitu tempat customer, warehouse, produksi, quality control (QC) dan warehouse barang jadi. Kemudian nilai RPN setiap masingmasing lokasi menjadi nilai RPN masing-masing Lokasi dapat dilihat tabel 8 berikut :

Tabel 8 Nilai RPN Masing-masing Lokasi

\begin{tabular}{lc}
\hline \multicolumn{1}{c}{ Lokasi Kegiatan } & Nilai resiko (RPN) \\
\hline Tempat Costumer & 39 \\
Warehouse bahan baku & 24 \\
Produksi & 280 \\
Quality Control (QC) & 39 \\
Warehouse barang jadi & 39 \\
\hline
\end{tabular}

Selanjutnya mengurutkan nilai RPN dari masing-masing lokasi tersebut dari yang terkecil sampai terbesar, nilai RPN per lokasi dapat dilihat pada Tabel 9 berikut.

Tabel 9 Hasil Pengurutan Nilai RPN Per-Lokasi

\begin{tabular}{lc}
\hline \multicolumn{1}{c}{ Lokasi Kegiatan } & Nilai resiko (RPN) \\
\hline Warehouse bahan baku & 24 \\
Tempat Costumer & 39 \\
Quality Control (QC) & 39 \\
\hline
\end{tabular}




\begin{tabular}{lc} 
Warehouse barang jadi & 39 \\
Lantai Produksi & 280 \\
\hline
\end{tabular}

Juga selanjutnya nilai-nilai RPN tersebut dilakukan perhitungan nilai rata-rata nilai Risk Priority Number (RPN) untuk mencari nilai tengah, quartil atas dan quartil bawah dengan persamaan (2) dan (3).

1. Rata-rata nilai $\mathrm{RPN}=\frac{421}{5}=84,2$

2. Nilai Tengah $=\frac{5}{2}+0,5=3$ (nilai ke 3 )

Hasil perhitungan bahwa nilai tengah maka bisa dijadikan patokan untuk menentukan quartil atas dan quartil bawah, sehingga nilai kuartil atas dan bawah ditentukan sebagai berikut:

1. Kuartil atas adalah nilai di atas nilai tengah (3), maka didapatkan hasil yaitu data 4 sampai dengan data 5 .

2. Kuartil bawah adalah nilai di bawah nilai tengah (3), maka didapatkan hasil yaitu data 1 sampai dengan data 2.

Dari hasil analisis sebelumnya ditemukan nilai RPN kegiatan yang paling aman dan paling minimum tingkat kecelakaannya yaitu kegiatan $\mathrm{N}$ proses water rising 5 , dan kegiatan $\mathrm{O}$ proses drying. Sedangkan kegiatan yang paling beresiko kecenderungan kecelakaan yang paling tinggi pada kegiatan E proses degreasing, G proses Pickling dan I Proses Elektroplating.

Kegiatan E, G dan I ini merupakan kegiatan yang harus mendapatkan perhatian khusus dari perusahaan agar bisa meminimalisir kecelekaan kerja. Sedangkan kegiatan J Proses water rinsing 3 dan L proses water rinsing 4 memiliki nilai resiko 3 masih cukup aman.

Untuk kegiatan D pengambilan part dari gudang dan M proses chroming mempunyai nilai resiko 8 dimana nilai resiko ini lebih tinggi dari kegiatan $\mathrm{J}$ dan L namun masih dalam kuartil bawah yang menandakan kegiatan ini masih dalam kondisi aman namun tetap waspada. Kegiatan B Pengantaran Part oleh kendaraan dari customer, Q proses inspeksi yang dillakukan oleh tim Quality Control dan S proses pengantaran part atau barang jadi kepada customer menggunakan kendaraan merupakan kegiatan yang paling beresiko di kuartil bawah yang memiliki nilai resiko sebanyak 15 sehingga kegiatan ini lebih beresiko dibanding kegiatan D dan M.

Untuk kegiatan K pemisah antara kuartil atas dan kuartil bawah yang memiliki nilai resiko sebesar 16 dimana ini merupakan nilai yang berada diatas kegiatan $\mathrm{B}$, Q dan S, maka kegiatan ini perlu diperhatikan oleh perusahaan. Dimana kegiatan K ini adalah proses activating. Selanjutnya ada serangkain kegiatan yang termasuk kuartil atas sehingga perlu mendapatkan perhatian serius dari perusahaan dimana kegiatan nya yaitu meliputi kegiatan A, C, F, H, P, dan R. Kegiatan ini memiliki nilai resiko sebanyak 24 dimana kegiatan ini memiliki nilai resiko yang lebih tinggi dari $\mathrm{K}$, dan berada dibawah satu level dari kegiatan yang palling beresiko yaitu $\mathrm{E}, \mathrm{G}$ dan $\mathrm{I}$. 
Kegiatan ini yaitu A adalah Pengangkutan Part atau barang setengah jadi (1), kegiatan C adalah Penurunan Part, kegiatan $\mathrm{F}$ adalah Proses water rinsing 1, kemudian $\mathrm{H}$ adalah proses water rinsing 2, kegiatan $\mathrm{P}$ adalah proses pemindahan part dan yang terakhir $\mathrm{R}$ adalah kegiatan pengangkutan part atau barang jadi (2).

Kemudian akan dibahas nilai resiko atau RPN sesuai lokasi dimana, lokasi yang mendapatkan nilai resiko yang paling kecil adalah warehouse bahan baku, dengan jumlah nilai resiko sebesar 24. Walaupun mendapatkan nilai resiko yang paling sedikit namun perlu juga untuk diwaspadai dan jangan disepelekan, lalu ada tiga lokasi yang mempunyai nilai resiko yang sama dan melebihi nilai resiko dari lokasi warehouse bahan baku dengan bobot nilai resiko sebanyak 39 dimana lokasi ini perlu diperhatikan perusahaan secara seksama. Tiga lokasi tersebut adalah tempat kostumer, tempat kualiti kontrol dan warehouse barang jadi. Dan yang terakhir, yang memiliki nilai resiko tertinggi dalam lingkup perlokasi adalah Lantai Produksi yang memiliki nilai resiko sebanyak 240. Nilai resiko tersebut jauh diatas lokasi yang lain sehingga lokasi ini harus mendapatkan perhatian khusus dari perusahaan.

\section{Kesimpulan}

Berdasarkan hasil penelitian bahwa proses kegiatan yang memiliki nilai resiko berdasarkan penilaian Risk Priority Number (RPN) yang paling kecil atau rendah adalah kegiatan Proses Water rinsing $5(\mathrm{~N})$ dengan nilai RPN 1, dan juga kegiatan Proses drying $(O)$ dengan nilai RPN 1 , artinya kedua kegiatan proses tersebut memiliki potensi bahaya yang sangat rendah. Sedangkan kegiatan yang memiliki nilai resiko berdasarkan penilaian Risk Priority Number (RPN) paling besar adalah kegiatan Pelaksanaan proses degreasing (E) dengan nilai 64, kegiatan Pelaksanaan proses pickling (G) dengan nilai 64, dan kegiatan Pelaksanaan proses electroplating (I) dengan nilai 64. Dengan nilai RPN terbesar menunjukkan kegiatan tersebut harus diprioritaskan untuk dilakukan pengendalian K3. Dengan demikian, maka pengendalian dengan cara perusahaan dapat dilakukan pengawasan yang ketat kepada para pekerja agar bisa bekerja sesuai dengan standar operasional prosedur (SOP), diharapkan perusahaan agar menyediakan Alat Pelindung Diri (APD) yang memadai, serta beberapa lubang yang terdapat pada jalur produksi agar bisa diperbaiki atau ditambal agar menciptakan lingkungan kerja yang kondusif.

\section{DAFTAR PUSTAKA}

[1] Badan Pusat Statistik, "Direktori Industri Manufaktur," bps.go.id, 2019. (Diakses pada 29 September 2020)

[2] bps.go.id, “Angka Kecelakaan Kerja Center," bps.go.id, 2019. (Diakses pada 29 September 2020)

[3] N. N. Putri, "Zero Accident, 1.052 Perusahaan Diganjar Penghargaan oleh Kemnaker," detik.com, 2019.

[4] Elphiana E.G, Yuliansyah M. Diah, \&. M. Kosasih Zen, "Pengaruh Keselamatan Dan Kesehatan Kerja Terhadap Kinerja Karyawan Pt. Pertamina Ep Asset 2 Prabumulih," JEMBATANB- J. Ilm. Manaj. Bisnis Dan Terap., no. 2, pp. 103-118, 2017.

[5] N. Wahyuni, B. Suyadi, and W. Hartanto, "Pengaruh Keselamatan Dan Kesehatan Kerja 
(K3) Terhadap Produktivitas Kerja Karyawan Pada Pt. Kutai Timber Indonesia," J. Pendidik. Ekon. J. Ilm. Ilmu Pendidikan, Ilmu Ekon. dan Ilmu Sos., vol. 12, no. 1, p. 99, 2018, doi: 10.19184/jpe.v12i1.7593.

[6] M. Dian Putri and W. Anik Setyo, "Pengetahuan, Sikap, Kebijakan K3 Dengan Penggunaan Alat Pelindung Diri Di Bagian Ring Spinning Unit 1," J. Heal. Educ., vol. 2, no. 1, pp. 33-38, 2017, doi: 10.15294/jhe.v2i1.18823.

[7] Ade Sofyan, "Pengaruh Kesehatan Dan Keselamatan Kerja (K3) Terhadap Kinerja Karyawan Pt. Bekaert Indonesia Plant Karawang," J. Manaj. dan Bisnis Kreat., pp. 2245, 2017, [Online]. Available: journal.ubpkarawang.ac.id.

[8] E. Darmayanti, "Perlidungan Hukum Terhadap Pelaksanaan Keselamatan Dan Kesehatan Kerja (K3) Pada Perusahaan," JCH (Jurnal Cendekia Hukum), vol. 3, no. 2, p. 283, 2018, doi: $10.33760 /$ jch.v3i2.21.

[9] F. Pangkey, G. Malingkas, and D. Walangitan, "Penerapan Sistem Manajemen Keselamatan Dan Kesehatan Kerja (Smk3) Pada Proyek Konstruksi Di Indonesia (Studi Kasus: Pembangunan Jembatan Dr. Ir. Soekarno-Manado)," J. Ilm. Media Eng., vol. 2, no. 2, p. 97452, 2012.

[10] S. Andiyanto, A. Sutrisno, and P. Charles, "Penerapan Metode Fmea (Failure Mode And Effect Analysis) Untuk Kuantifikasi Dan Pencegahan Resiko Akibat Terjadinya Lean Waste," J. Online Poros Tek. Mesin, vol. 6, no. 1, 2017.

[11] R. Projo Mukti and S. Sriyanto, "Analisis Kecelakaan Kerja Dengan Metode Failure Mode And Effect Analysis (Fmea) Studi Kasus : Automotive Workshop Semarang," $e$ journal UNDIP, pp. 1-7, 2017.

[12] Shift, "10 Langkah Lakukan FMEA,” Shift Indonesia, 2013.

[13] Nuriawati Linda and I. I. Ketut, "Evaluasi Penerapan Keselamatan Dan Kesehatan Kerja ( K3 ) Berdasarkan FTA, FMEA Dan PHA Di Jurusan TITPL SMK Negeri 1 Magelang," vol. 8, no. 6, pp. 490-501, 2018.

[14] Y. Sakti, "Analisis Penyebab Insiden Kerja Dengan Pendekatan Failure Mode And Effect Analysis (Fmea) Dan Penerapan Sistem K3 (Keselamatan Kesehatan Kerja) Di Area Pertambangan Batubara Pada 'PT.X,'” J. Tek. Ind., vol. 19, no. 02, pp. 15-24, 2017. 